Permission to land

The delays experienced by the EEC's Joint European Torus (JET) fusion project are over. Chris Sherwell reports

A Fur.L two years after the matter came before it, the EEC Council of Research Ministers has agreed on the research laboratories at Culham near Oxford as the location for the next stage of the Community's fusion project, JET. The choice, made at a Council meeting on Tuesday, ends a controversial wrangle that has damaged the Community as well as the project. The decision also paves the way for the establishment of a JET Council, the release of funds to boost a stalling research effort and the appointment of a project head.

Political rather than scientific disputes have persistently hamstrung the $£ 100$-million project. Contracts for the team based at Culham have had to be extended at the last moment many times, and continuing uncertainties have driven some members away. Only last week Paul Rebut, the present project leader and a strong candidate to head the next phase, warned that rebuilding the team would take at least six months. Over the past 18 months JET has come up at five Research Ministers' meetings, two Foreign Ministers' meetings and one heads of government meeting; there have been six elections, and seven research ministers have changed; so have six foreign ministers and four heads of government.

The site of the project has sparked most controversy. National interest arguments prevented agreement on any of the four sites originally pro- posed (Ispra in Italy, Cadarache in France, Garching in Germany and Culham in Britain), even when they were eventually whittled down to Garching and Culham. A widely expected decision failed to materialise at a Research Council meeting in March this year, and EEC heads of government passed the matter three months later to the Foreign Ministers. When they too failed to agree, everything seemed to hang on AngloGerman exchanges. But the Schleyer kidnapping intervened, no exchanges took place and JET was not discussed at a Foreign Ministers' meeting in September.

The breakthrough finally came last week when the West German Chancellor, Helmut Schmidt, and the UK Prime Minister, James Callaghan, met in the aftermath of the successful Mogadishu raid. Its euphoric effects, and Britain's supporting role in it, may have helped the two men submerge differences on matters like Community budget contributions. They agreed that a site for JET should be decided by a consensus -in other words, that neither country would veto whatever preference the majority expressed. This was conveyed to the Foreign Ministers' meeting in Luxembourg the same day, and though Germany did not waive her claim for Garching, the immediate presumption, based on past voting intentions, was that JET would go to Culham when the Research Ministers met in Luxembourg. In the event, five countries voted for Culham and two for Garching. One of the two abstaining countries went with the majority. Earlier fears of an Irish veto proved unfounded.

Reports that two JET projects were being discussed gained credence at a press conference in Brussels on Mon- day given by Guido Brunner, the EEC's Energy and Research Commissioner. Culham and UK Foreign Office spokesmen last week discounted the idea, the former pointing out that even if this referred to the possibility of siting 'Super JET' or 'Jumbo JET' (as the next phase is known) in the country which failed to win JET, such a decision could not be taken bilaterally. The impression nevertheless remained on Monday that the Research Ministers would take a consensus view on locating the next phase at the losing site, and that ancillary fusion research might also be used as compensation.

The removal of other potential obstacles at a meeting of high-level officials a week earlier also assisted agreement on a JET site. Helpful concessions from France, which originally proposed a JET Council to manage the project and saw it become a stumbling block, produced agreement that the member states, along with other participating countries (Sweden and Switzerland), would each have two members on it, one a scientific expert. Voting will be weighted, 26 out of 37 constituting a majority. The Council, which will have a scientific council to consult at its convenience, will meet as and when necessary. Once it is established (initially in interim form) and funds become available, the senior scientific appointment for the project will be made. But that could prove as politically contentious as anything that has befallen JET so far.

The aim behind the $£ 100$-million project-often forgotten by the politicians, often simplified as "cheap, safe and abundant energy supplies"is essentially to construct a thirdgeneration tokamak device. The equivalent device in the USSR is known as T-20, in the USA as TFTR, and in Japan as T-60.

\title{
DIOXIN
}

\section{Informing on 2,4,5-T}

Alastair Hay looks at two recent reports on the controversial herbicide 2,4,5-T

Manufacturers and users of the herbicide $2,4,5-\mathrm{T}$ are not letting attacks on it pass without comment, if two recent reports that attempt to vouch for its safety are anything to go by. The first, a Dow Chemical Company report to the US Environmental Protection Agency (EPA), insists that there is no "significant hazard" to humans asso- ciated with its use. The second, from the UK Forestry Commission, claims that if foodstuffs or water supplies should become contaminated with $2,4,5-\mathrm{T}$, "serious consequences [for humans or animals] are unlikely" to occur.

The use of 2,4,5-T has aroused concern since the late 1960 s when formulations of the herbicide in use in Vietnam were shown to be contaminated with 2,3,7,8-tetrachlorodibenzo-p-dioxin (dioxin), which is highly toxic and a known teratogen. The public outcry, together with scientific criticism of the use of 2,4,5-T, led the EPA to prohibit its use around homes, recreational sites, aquatic areas and on human food crops. In 1975 an EPA study reported that dioxin had been found in beef fat taken from cattle in areas where $2,4,5-T$ was known to have been used.

The Dow study was undertaken to assess these EPA findings. In a twoyear study Dow scientists fed rats diets containing $0.1,0.01$ and $0.001 \mu \mathrm{g} \mathrm{kg}^{-1}$ of dioxin a day. The animals receiving the highest dose experienced the known clinical and pathological symptoms of dioxin exposure-decreased weight gain, decreased red blood cell and 
haemaglobin levels, elevation of some serum enzymes, and increased mortality. Discernible increases in the incidence of liver cancer and carcinomas of the lung, hard palate and tongue were also observed. But the report also speaks of a remarkable decrease in the "incidences of tumours of the pituitary, uterus, mammary glands, pancreas and adrenal gland" in these animals. In the rats receiving the lower doses of dioxin a lesser degree of toxicity was observed but there was no increase in tumours. On the basis of these results the report states that if the EPA measurements are used then the average person would need to consume fifty times his "body weight in beef every day to receive the daily dose level" of dioxin linked with cancer incidence in Dow's studies. Thus, in Dow's view it appears that 2,4,5-T is safe if used properly.

The same conclusion is drawn by the Forestry Commission report, 'The Safety of Herbicides 2,4-D and 2,4,5-T'. The author, D. J. Turner, describes many of the criticisms of the use of 2,4,5-T as unfounded and ill-informed. He points out that 2,4,5-T, still enjoying widespread use in Europe and South-East Asia, remains the most effective herbicide for defoliating rubber trees, which is the way to contain and isolate the South American leaf blight disease Dothidella ulei. But he also says that "if reaction conditions [for converting tetrachlorobenzene to trichlorophenol-the precursor of 2,4,5-T] are properly regulated dioxins are not formed". Chemists knowledgeable in reaction mechanisms say this is not so, arguing that the reaction makes dioxin contamination unavoidable and that control of the reaction conditions will only limit the amount of dioxin produced, not eliminate it entirely. In their view the manufacturing stage presents greater risks of dioxin contamination than the use of the herbicide in silviculture.

In spite of the now considerable volume of literature relating to dioxin's effects, the report claims there is no evidence that the "defoliation spraying programmes in Vietnam had any direct effects on humans". This is flatly contradicted in the fifteenth report of the International Agency for Research on Cancer (IARC). In a chapter on chlorinated dibenzodioxins that cites the same National Academy of Sciences report referred to in the Forestry Commission publication, this states that the Montagnard people of South Vietnam were badly affected by exposure to the herbicide 'Agent Orange', a 50:50 mixture of the $n$-butyl esters of 2,4-D and 2,4,5-T, containing up to $30 \mathrm{mg} \mathrm{kg}^{-1}$ of dioxin. The consequences included diarrhoea, vomiting, skin rashes, fever, abdominal pain and the deaths of some children. The IARC publication, one of the most comprehensive reports yet produced on the dioxins, aimed to assess carcinogenicity of chlorinated dibenzodioxins, but concluded that this evaluation could not be made with the data available to it at the time of publication.

At Séveso in Italy-where the authorities are now satisfied that decontamination following last year's release of dioxin has made it safe for people to return to their homes (last week the first 24 families were allowed back) -135 ohildren have chloracne as a result of dioxin exposure. A total of thirty-three adults but no children have neurological disorders, yet if (as some argue) chloracne is an obligate sign of dioxin poisoning, children might have been expected to have neurological problems. No eye damage has been reported in the 400 people examined by an oculist. Sixteen cases of children born with malformations were reported by August this year, of whom two died, but the diversity in the type of malformation and the fact that the number was no greater than the statistical norm suggests that dioxin was probably not the causative agent.
THE development of a new chelating agent does not usually make headlines in the national press, but this week saw the widely publicised announcement of a chelating agent with two important differences. Its scientific interest lies in the fact that it can enter the cells of the body and will therefore be much more efficient at removing heavy metal contamination. The reason it hit the headlines is that it has been developed (at the Harwell laboratories of the UK National Radiological Protection Board) to remove plutonium from the body in the event of an accident.

One of the problems in devising effective treatments for the rare cases of accidental contamination with plutonium has been the difficulty of removing the plutonium which becomes locked up in the cells of the body, mostly in liver and bone, where over the years there is the risk that it might induce cancers. The only available treatment up to now aimed to inactivate the plutonium when it was freely accessible in the blood before it became deposited inside tissue cells. The chelating agent calcium $\bar{d}$ iethylene-triamine-pentaacetic acid (CaDTPA) can pick up plutonium from the bloodstream and the resulting complex is excreted in the urine.
But CaDTPA has one great drawback--it cannot enter cells and so is only effective against plutonium circulating in the blood. In real life the

\section{Fighting plutonium}

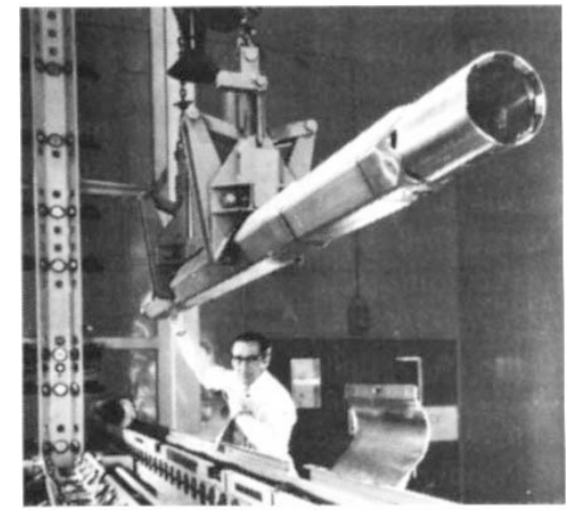

BACKGROUNDER

contaminant may well be 'insoluble' plutonium, such as plutonium dioxide particles, which leach very slowly into the bloodstream from the lungs; in this case DTPA is not particularly efficient in reducing the total body burden.

The NRPB's new drug, which it calls Puchel, is a derivative of DTPA with one important modification. Fatty acid chains have been added to the molecule enabling it to penetrate the lipid cell membrane and pick up plutonium from inside the cell. The complex is then excreted, mostly in the faeces. The NRPB is not yet divulging the structure of its new molecule, pending a possible patent application, but the secret apparently lies in the length of the fatty acid chains.

So far, of course, the drug has only been tried out in animals, where it has proved essentially non-toxic when given as the calcium salt. Injected intraperitoneally into hamsters it released most of the plutonium deposited in the liver after injection of a soluble plutonium salt, and given as a aerosol removed plutonium from the lung after inhalation of plutonium particles. It will also probably be effective in removing intracellular metal if given orally. Puchel has proved less effective at releasing plutonium from bone than from liver.

Puchel has been developed as a contribution towards reducing the risks of a nuclear accident, but if it proves itself it may be useful in cases of poisoning with non-radioactive heavy metals such as lead and mercury. 